\title{
A Review of State-Level Policies on Electrical Energy Storage
}

\author{
Jeremy Twitchell ${ }^{1}$
}

Published online: 22 April 2019

(C) The Author(s) 2019

\begin{abstract}
Purpose of Review Since California adopted its energy storage mandate in 2013, 14 other states have developed energy storage policies designed to encourage adoption or reduce barriers. This paper reviews those efforts to identify what types of policies are being developed, the underlying goals and rationale behind different approaches, and the early outcomes of those policies.

Recent Findings State activity related to energy storage has accelerated in recent years, and numerous policies have emerged. Generally, those policies take one of two approaches: facilitating operational experience with energy storage by ensuring its presence on the grid, or enabling future deployments by removing or reducing barriers. Through detailed review of state policy actions, this paper explores the drivers, design, and implementation of these five specific types of energy storage policy.

Summary A taxonomy of state policies related to energy storage is presented, as well as recent research findings that support the different approaches and specific examples of how, where, and why those policies have been implemented. Finally, early impacts of these policies are considered.
\end{abstract}

Keywords Energy storage $\cdot$ Integrated resource plan $\cdot$ State energy policy $\cdot$ Energy regulation $\cdot$ Storage mandate

\section{Introduction}

Two defining characteristics of energy storage are its flexibility and scalability. Energy storage devices can respond instantly to grid changes and can be sized to provide services behind the customer's meter, at the distribution system, or at the bulk power system. Those characteristics, however, do not neatly fit within traditionally defined utility functions such as generation, transmission, and distribution, and integrating energy storage into traditional regulatory structures has been challenging as a result [1].

In territories that belong to competitive, regional markets, generation investment decisions are driven by market signals. In those markets, the Federal Energy Regulatory Commission (FERC) has issued several orders in recent years that collectively aim to align market structures with the capabilities of energy storage. ${ }^{1}$

${ }^{1}$ See FERC Order 755, Order 792, Order 841, and Order 845.

This article is part of the Topical Collection on Energy Storage

Jeremy Twitchell

jeremy.twitchell@pnnl.gov

1 Pacific Northwest National Laboratory, 902 Battelle Boulevard, Richland, WA 99354, USA
Outside of those markets, however, vertically integrated utilities make investment decisions with input from integrated resource plans (IRPs) or similar planning activities. Those plans inform utility investment decisions by identifying resource values based on the utility's needs and system characteristics.

Traditional models that utilities use in IRPs, however, generally lack the ability to capture resource benefits at a subhourly scale or at the distribution and customer levels, meaning that many of the flexibility and locational benefits of energy storage are not captured in the resource planning process. To develop models that account for those benefits, utilities and regulators must first understand what those benefits are and how they interact with one another [2••]. As utilities better understand the values of energy storage and account for them in resource planning, they are more likely to identify energy storage as part of a cost-effective resource portfolio [3].

Where utilities do not have access to competitive markets to guide cost-effective storage deployments, state policies can provide a substitute by ensuring that the capabilities and values of energy storage are incorporated into regulatory processes such as system planning, resource procurement, and rate design. To that end, states have enacted multiple policies in recent years.

Those policies are driven by various mechanisms: a governor's executive order, legislation, or a utility commission 
investigation. They also differ in how aggressive they are; some policies require storage investments, others seek to facilitate them through incentives, and still others aim to increase access for energy storage by removing barriers in existing policy and regulatory processes.

In reviewing these policies and the processes by which they were established, common themes and approaches become clear. This paper presents a taxonomy for classifying and studying state energy storage policies, reviews the research that supports those policies, and considers the impact of state policies on current and future storage deployments.

\section{Taxonomy of State Energy Storage Policies}

At present, 15 states have adopted energy storage policies. While other policy activities related to grid modernization may tangentially involve energy storage, and several utilities have independently pursued energy storage investments, this review is limited to policies that specifically address energy storage that were developed under a state authority.

Pacific Northwest National Laboratory (PNNL) has identified five types of state-level energy storage policies: procurement targets, regulatory adaptation, demonstration programs, financial incentives, and consumer protections [4]. Procurement targets are mandates set by the state that require utilities to acquire a specified quantity of energy storage. Regulatory adaptation refers to changes made in state energy regulations that are designed to create opportunities for energy storage. Demonstration programs are those in which the state explicitly authorizes, and in many cases funds, energy storage projects for the purpose of exploring their operation. Financial incentives are direct subsidies or tax credits available to enduse customers for installing behind-the-meter storage devices. And finally, consumer protections are policies that establish certain rights for customers who install energy storage. Figure 1 summarizes the policies adopted in each state.

\section{Procurement Targets}

Procurement targets have generally been adopted where a state has identified specific issues that energy storage is expected to address, and current practices that may prevent storage from adoption in the normal course of business. Generally, procurement targets provide a supportive signal for investors and reduce regulatory uncertainty associated with new technologies [5]. In the case of energy storage, targets are a direct way to ensure investment when there is a lack of operational data and experience to support an accurate analysis of the technology [1].

Market transformation, or the development of new, costcompetitive energy storage technologies, is another goal of certain targets. In California, the California Public Utilities
Commission (CPUC) interpreted the legislature's directive to encourage a range of energy storage technologies to mean that there needed to be room for competition within the target, and so it limited the size of eligible pumped storage facilities to $50 \mathrm{MW}$, over the objection of some stakeholders, such as pumped storage hydropower developers for whom economy-of-scale is significant [6].

Beyond the installed projects and market impacts of procurement targets, it is their accompanying procedural requirements that are driving systemic change in the way that utilities evaluate and select resources. Whether a legislature deferred determination of the target to regulators (as was done in California, Colorado, Massachusetts, Nevada, and New York) or established the target itself (as was done in Oregon and New Jersey), every legislature directed utilities and regulators to determine the optimal approach to comply with the target.

In the first such proceeding, the California legislature directed the CPUC to consider the ability of energy storage to integrate renewables, displace fossil fuels, and defer or eliminate infrastructure investments in the transmission and distribution systems [7]. That direction led the CPUC to break the target into buckets for transmission-, distribution-, and customer-connected projects, and to develop guidance for the cost-effectiveness tests that utilities should apply to storage projects [6]. While other states have followed the broad California template, no other state has broken down procurement targets into subcategories by point of interconnection.

The potential roles for energy storage that legislatures have directed regulators to study in other states is generally similar to those identified in California. In New Jersey, legislators' top priority was for energy storage to provide emergency back-up power for critical loads. And though the New Jersey Legislature set targets in statute in 2018, it directed state regulators to conduct a yearlong study to identify the optimal uses for energy storage in the state before initiating a proceeding to implement the target [8].

Oregon legislators also established that state's target and directed the Oregon Public Utilities Commission (OPUC) to establish expectations for how utilities should conduct their analyses and propose their projects [9]. Process became a key outcome of the OPUC proceeding; in approving the utilities' proposed projects to comply with the target, commissioners required them to develop a detailed plan for improving their ability to analyze energy storage in the IRP process [10].

\section{Regulatory Adaptation}

Rising penetration of variable, renewable generation increases the need for system flexibility; hence, there is a strong corollary between renewable energy portfolio (RPS) standards and energy storage policies. Every one of the 15 states studied in this paper 
Fig. 1 Summary of state energy storage policies
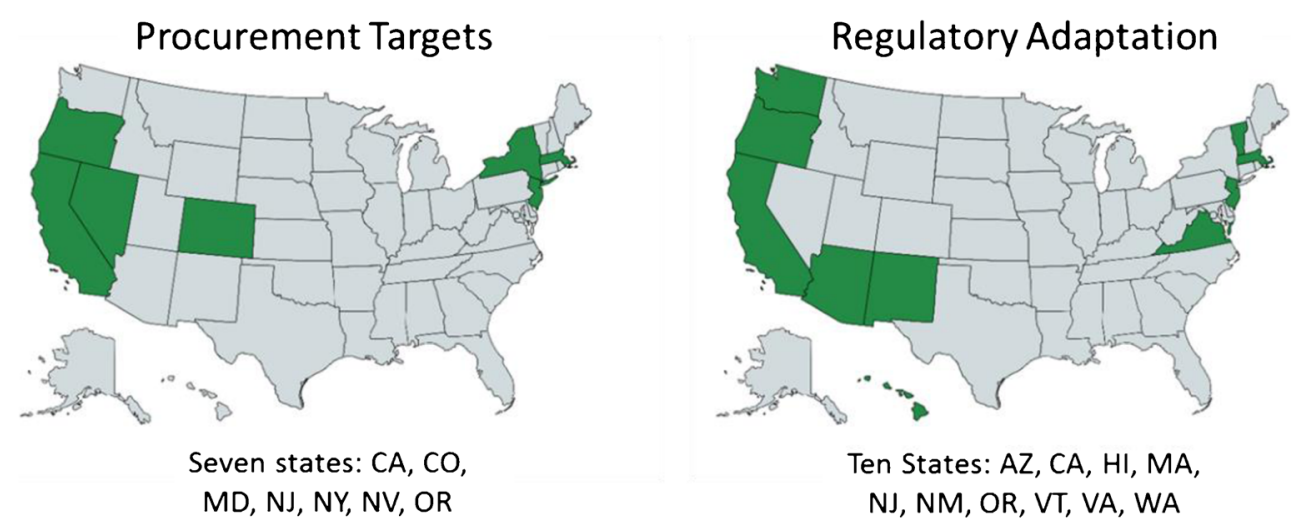

Demonstration Projects

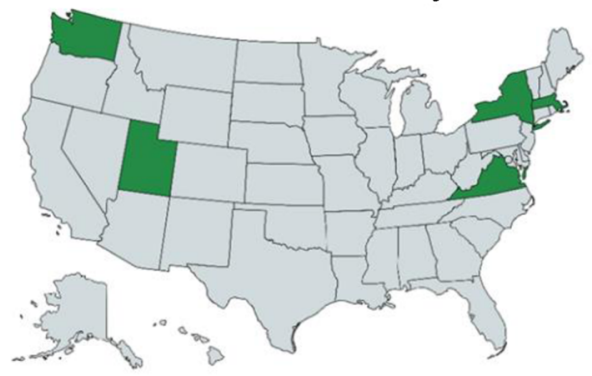

Five states: MD, NY, UT, VA, WA

Financial Incentives

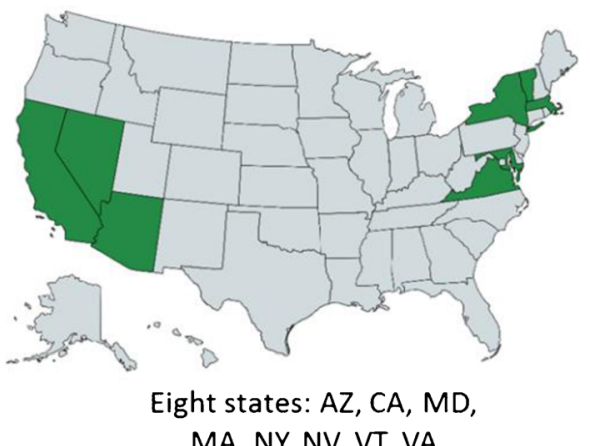

Consumer Protections

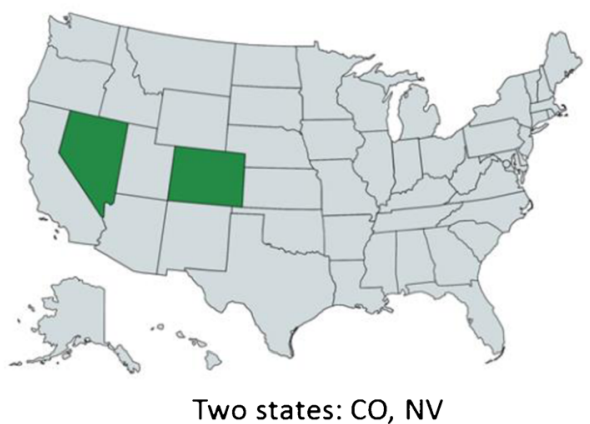

has an RPS, or in the case of Utah and Virginia, a non-binding renewable energy goal. Six states and Washington, D.C., have each adopted an RPS of $50 \%$ or more; all six states (California, Hawaii, New Jersey, New York, Oregon, and Vermont) have adopted storage policies, and Washington, D.C., has an active regulatory proceeding involving storage [11].

Energy storage can be a cost-effective source of renewable integration, but identifying those opportunities requires a holistic view of storage that economically optimizes all of its capabilities - something standard IRP models are not designed to do [12]. Developing policies to fully account for the benefits of energy storage in planning and procurement targets is an enabling step toward building sufficient flexibility into the system to accommodate a high-renewable future [13].

In 10 states, regulators have adapted regulatory processes to incorporate the flexibility and peak-reducing benefits of energy storage into their proceedings. Less prescriptive than procurement targets, these policies are intended to broaden competitive access for energy storage. How this is accomplished varies among states; some efforts have focused on updating resource planning requirements, while others have amended ratemaking processes.

In Washington State, regulators developed a planningoriented approach to energy storage. In its report that initiated the proceeding, staff at the Utilities and Transportation Commission argued that energy storage could enable the state to reach its long-term renewable energy goals, but that policy guidance was necessary to ensure that utilities incorporated lessons from state-funded demonstration projects into future planning efforts [12]. The proceeding culminated in a policy statement that identified energy storage as a key enabling technology to meet the state's clean energy goals and providing guidance for how utilities should include storage in the resource planning process [14]. 
In January 2018, more than 4 years after adopting its procurement target, the CPUC adopted 11 new planning rules that require utilities to consider the multiple uses of energy storage in their resource planning. The commission reasoned that since contemporary market rules failed to compensate energy storage resources for all of the values that they could provide to the grid, utilities must account for those uncompensated values in their planning to ensure that the full economic value of energy storage is reflected in resource decisions [15].

In two separate decisions, the Hawaii Public Utilities Commission (HPUC) leveraged other regulatory mechanisms to facilitate storage projects that help the state meet its aggressive renewable energy goals. First, to manage the rapid growth of distributed solar, HPUC amended its interconnection rules to require new solar customers to either consume all generation on site or export generation to the grid at time-of-use (TOU), nonretail rates [16]. Both policies create strong use cases for energy storage: the addition of a storage system to a solar array would help customers to effectively utilize generation on site (and such customers would be eligible for an expedited interconnection process), or to shape the solar generating profile for export to the grid during high-value periods.

In another decision, HPUC created the Major Project Interim Recovery Mechanism, which incents utilities to invest in infrastructure that enables renewable generation by allowing utilities to place those costs into customer rates outside of a general rate case [17]. In May 2018, the Hawaiian Electric Companies filed applications for two energy storage projects totaling $120 \mathrm{MW}$ under the mechanism.

In Arizona, the Arizona Corporation Commission (ACC) identified a need for energy storage to reduce peak demand. Because load management was the sole focus, the ACC expanded the demand-side management program of utility Arizona Public Service in 2016 to include a $\$ 4$ million pilot program to install and aggregate customer-sited energy storage devices [18].

\section{Demonstration Projects}

Demonstration projects allow a state to study the benefits and logistics of energy storage deployment on an incremental basis. A study of 15 energy storage demonstration projects funded by the American Recovery and Reinvestment Act found that the projects allowed participants to better understand the permitting and construction challenges involved in developing energy storage projects, illuminated deficiencies in current building and electric codes, and generally allowed for operators to learn the operational and economic characteristics of energy storage in a lowerrisk, lower-cost setting [19].

Five states have adopted a programmatic approach to energy storage demonstration projects. While each state generally identifies a need for improved understanding of how energy storage operates on the grid, three models for pursuing that goal have emerged: funded, authorized, and facilitated.

In the funded model, the goal is for public study and dissemination of lessons learned from the project. To that end, states provide funding in exchange for operational data from funded projects. Washington was the first state to employ this model, providing \$14.3 million in 2013 through the state's Clean Energy Fund to assist utilities in deploying four battery storage projects that explored differing chemistries and various use cases. The state also retained PNNL to conduct detailed analysis of the projects and the various use cases that each one tested. Preliminary reports identifying various use cases for testing [20] and system controls [21] have been completed, with full economic evaluations of each project forthcoming.

In 2017, Massachusetts developed a similar program, Advancing Commonwealth Energy Storage (ACES). The state provided $\$ 20$ million in grants to energy storage projects that test various, multi-use business cases for energy storage. The goal of the program is to identify valuable, replicable combinations of value streams to drive further energy storage deployment in the state [22]. Grant recipients will be required to provide 3 years of detailed project operational data to state agencies for analysis [23].

Under the authorized approach, a state allows a utility to invest in a demonstration project, but does not contribute funding or require reporting. In Utah, state legislators directed the Utah Public Service Commission to authorize certain funds for "innovative utility programs" designed to investigate, among other options, energy storage technology [24]. The commission later granted a request from utility Rocky Mountain Power to develop a $\$ 7$ million solar and storage project to provide voltage support on a section of the company's transmission and distribution systems that would otherwise require infrastructure upgrades [25].

The final model, the assistive approach, has been pioneered by New York as part of its Reforming the Energy Vision (REV) initiative. In this model, the state acts as a facilitator between developers and utilities. Through the REV Demo program, the state maintains an open call for demonstration project proposals that will test new technologies and business models for energy storage and other distributed energy resources. Independent evaluators vet project proposals, provide feedback and guidance, and match accepted proposals with utilities and other market providers for further consideration and potential development agreements [26]. To date, four energy storage projects have been developed through this process [27].

\section{Financial Incentives}

Customer investments in behind-the-meter (BTM) energy storage technology accelerated in 2018, as the approximately $45 \mathrm{MW}$ of BTM storage installed in the second quarter constituted the largest quarter to date, and accounted for $75 \%$ of all installed storage capacity during the period [28]. Much of the 
BTM development activity to date has taken place in jurisdictions that have adopted TOU rates, where higher rates during highdemand periods send an economic signal for customers to reduce their usage or meet some of their demand through customer-sited resources such as energy storage. As such rates are common for larger commercial and industrial customers, most BTM capacity to date has been installed by those customers [29॰].

BTM storage has the potential to cost-effectively defer infrastructure upgrades and reduce system peaks, but enabling it to do so depends on the right balance of scale, integration, control, and incentives (through direct financial subsidies or price signals communicated through rate design) [30]. Several states have begun exploring this issue in recent years.

The largest and most systematic program is in California, which adjusted its longstanding Self-Generation Incentive Program (SGIP) in 2016 to focus on distributed resources that reduce emissions and provide grid benefits, and set aside more than $\$ 448$ million in funding for BTM storage [31].

Independent analysis of the SGIP storage program determined that peak reduction savings have been fairly smallthe $67 \mathrm{MW}$ of capacity in the program only reduced system peaks in 2017 by $2.4 \mathrm{MW}$ - because rate designs encouraged larger customers to prioritize other use cases over peak reduction. Changes to rate design that better align customer incentives with system needs would significantly enhance peak reduction, the analysis found [32].
In Arizona, a storage incentive program arose out of a 2017 rate case dispute, in which customers argued that Arizona Public Service's proposed demand charge structure limited their ability to capture savings by reducing their usage at peak. The ACC decided the matter by approving a pilot program proposed by the utility as a compromise, which will provide $\$ 2$ million to assist large commercial and industrial customers to install BTM storage for system peak reduction. To encourage longer-duration devices that discharge for the duration of peak periods, the incentive is prorated for devices with fewer than $5 \mathrm{~h}$ of discharge, and only large customers with TOU rates are eligible [33].

To test a different approach to storage incentives, Maryland in 2018 became the first state to offer a state income tax credit for energy storage, allowing up to $\$ 5000$ for residential customers and up to $\$ 75,000$ for commercial and industrial customers, subject to a program total of $\$ 750,000$ per year [34]. The tax credit was designed as a pilot program to test the effectiveness of tax credits in encouraging energy storage adoption [35].

\section{Consumer Protection}

Finally, two states have adopted legislation that guarantees certain protections to customers who install energy storage. Nevada's law, adopted in 2017, prohibits any rate or tariff based solely on a customer's ownership of energy storage and requires utilities to develop optional TOU rates [36]. Colorado followed in 2018

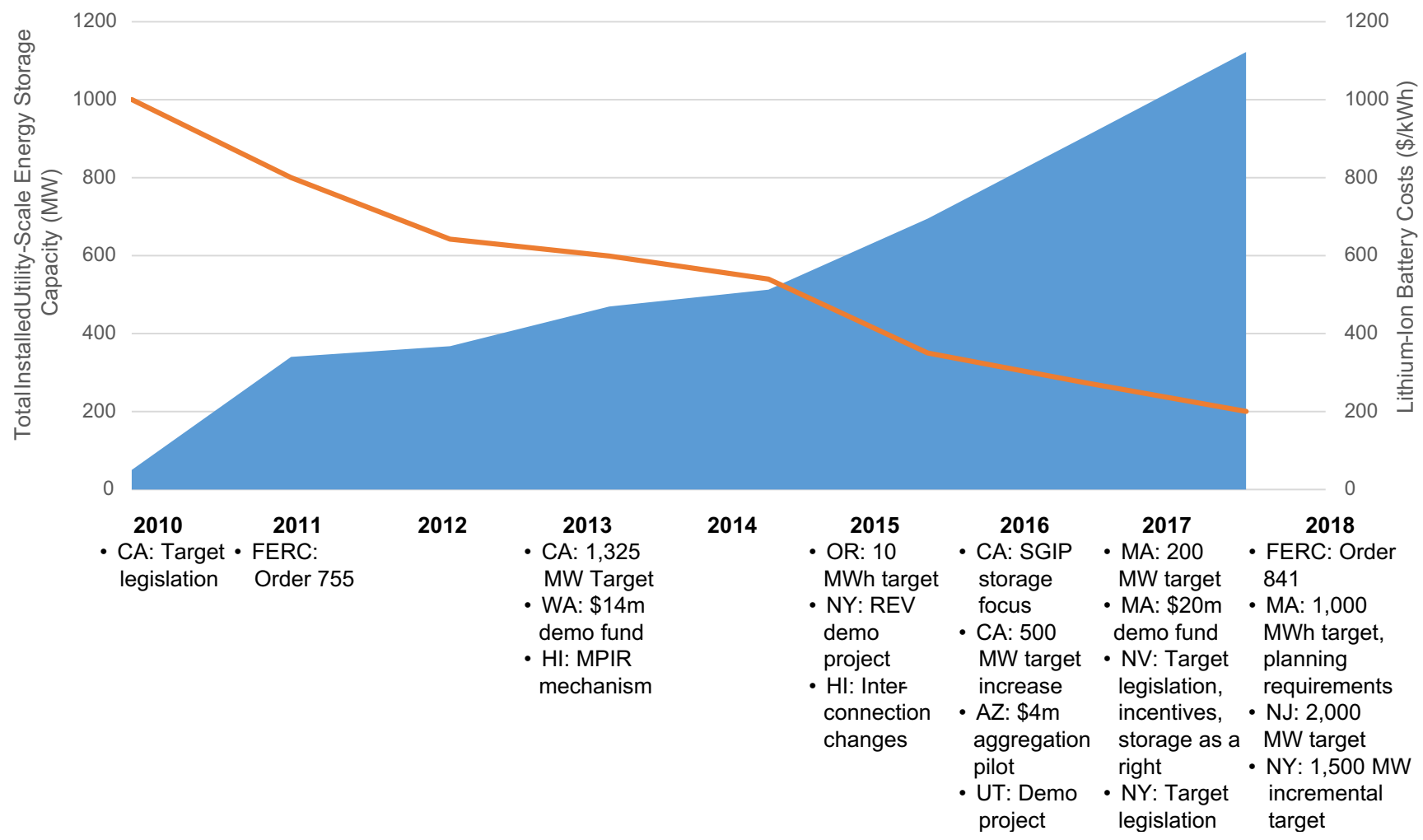

Fig. 2 Storage policies, installations, and costs since 2010 
with a law declaring that utility customers have a right to install energy storage and directing the Colorado Public Utility Commission to adopt rules to ensure timely, streamlined interconnection processes [37].

\section{Impact of State Policies}

Given the recent and still-developing nature of state energy storage policy activity, quantitative analysis of policy outcomes remains premature. However, some anecdotal evidence suggests that state policies are having an impact.

In Washington, for example, the initial staff report on how utilities were treating energy storage in IRPs argued that policy intervention was required because two utilities in the state refused to analyze storage in their 2013 IRPs [12]. In their 2017 IRPs, which were filed after the Washington Utilities and Transportation Commission issued draft guidelines in its storage proceeding, those same two utilities had included storage in their IRP model and selected it as part of their preferred resource portfolio [38, 39].

When California set its target in 2013, the CPUC granted a request by utilities and other stakeholders to build a deferment process into the target's timeline, in the event that market transformation did not occur in time for the utilities to cost-effectively reach targets [6]. At present, all three utilities are on track to meet the target without the deferment mechanism, and the state legislature added additional targets for BTM storage in 2016.

State policies are just one factor driving the growth of energy storage on the electric grid; a full analysis of their effectiveness would have to consider exogenous factors such as FERC policies, federal research and development programs, customer interests, market transformation driven by electric vehicle demand, and the interactions between those effects. Figure 2 presents trends in utility-scale storage deployments, energy storage system costs, and policy activity (including FERC) since 2010 [40, 41].

As Fig. 2 shows, from 2010 to 2017, the amount of utilityscale storage in the USA derived from resources other than pumped hydro and compressed air increased from $50 \mathrm{MW}$ to more than $1100 \mathrm{MW}^{2}$ The costs of a lithium-ion battery pack declined from about $\$ 1000$ per kilowatt-hour $(\mathrm{kWh})$ to about $\$ 200$ per $\mathrm{kWh}$ in the same period. Over that same period, state policy activity on energy storage also accelerated and is likely to have a significant impact on future investment levels. For example, the realization of adopted procurement targets alone will add more than $4600 \mathrm{MW}$ of additional storage capacity by $2030 .^{3}$

\footnotetext{
${ }^{2}$ Since market transformation is a goal of state policies, Fig. 1 omits pumped storage and compressed air, which are established technologies that saw little development during the period. Only one, 40-MW pumped storage facility was added during the period, and no compressed air facilities were added.

3 Includes 2000 MW for New Jersey's 2030 target, 1500 MW for NY's incremental 2025 target, 200 MW for Massachusetts' initial target, and approximately $900 \mathrm{MW}$ in the pipeline for California's 2020 target.
}

\section{Conclusion}

Driven by various needs and goals, state-level energy storage policy activity has accelerated in recent years. Given recent trends in cost declines and the growing body of research and operational experience that are contributing to a more complete understanding of the technology, it is reasonable to expect that states will continue to develop and refine policies in the coming years. In identifying and classifying existing policies and their underlying goals, this work provides a framework for future research on this topic as well as a reference for state policymakers who are exploring policy alternatives.

Funding Information This work was funded by the US Department of Energy, Office of Electricity.

\section{Compliance with Ethical Standards}

Conflict of Interest Jeremy Twitchell declares he was involved in the proceeding at the Washington Utilities and Transportation Commission referenced in the work as an employee of that agency.

Human and Animal Rights and Informed Consent This article does not contain any studies with human or animal subjects performed by any of the authors.

Open Access This article is distributed under the terms of the Creative Commons Attribution 4.0 International License (http:// creativecommons.org/licenses/by/4.0/), which permits unrestricted use, distribution, and reproduction in any medium, provided you give appropriate credit to the original author(s) and the source, provide a link to the Creative Commons license, and indicate if changes were made.

\section{References}

Papers of particular interest, published recently, have been highlighted as:

- Of importance

•- Of major importance

1. Kaufman S, Komor P, Langdon B, Vallett P. Energy storage in regulated markets: getting the rules right. Electr J. 2011;6:63-71. https://doi.org/10.1016/j.tej.2011.06.006.

2.• Balducci P, Alam MJ, Hardy TD, Wu D. Assigning value to energy storage systems at multiple points in an electrical grid. Energy Environ Sci. 2018;11:1926-44. https://doi.org/10.1039/ C8EE00569A. This article presents the most recent, holistic approach in valuing the multiple services provided by energy storage technologies, at every level of grid interconnection.

3. Cooke A, Twitchell J, O'Neil RS. Energy Storage in Integrated Resource Plans. Pacific Northwest National Laboratory (forthcoming).

4. Pacific Northwest National Laboratory. Energy Storage Policy Database.

5. Stein AL. Reconsidering regulatory uncertainty: making a case for energy storage, 41 Fla. St. U. L. Rev. 697 (2014), available at http:// scholarship.law.ufl.edu/facultypub/505. 
6. California Public Utilities Commission. Decision adopting energy storage procurement framework and design program. Rulemaking 10-12-007 (October 17, 2013).

7. Assembly Bill 2514 (2010), California State Legislature.

8. Assembly Bill 3723 (2018), New Jersey State Legislature.

9. House Bill 2193 (2015), Oregon State Legislature.

10. Oregon Public Utility Commission, In the Matter of Portland General Electric Company's Draft Storage Potential Evaluation. Order No. 18-290, Docket UM-1856 (August 13, 2018).

11. Public Service Commission of the District of Columbia, MEDSIS Working Group Portal. https://dcgridmod.com/.

12. Washington utilities and transportation commission staff. Modeling energy storage: challenges and opportunities for Washington utilities (May 17, 2015). Docket UE-151069.

13. Papaefthymiou G, Dragoon K. Towards $100 \%$ renewable energy systems: uncapping power system flexibility. Energy Policy. 2016;92(May):69-82. https://doi.org/10.1016/j.enpol.2016.01.025.

14. Washington utilities and transportation commission. Report and policy statement on treatment of energy storage Technologies in Integrated Resource Planning and Resource Acquisition, Docket UE-151069 (October 11, 2017).

15. California Public Utilities Commission. Decision on multiple-use application issues (January 11, 2018). Rulemaking 15-03-011.

16. Hawaii Public Utilities Commission. Decision and Order No. 33258 (October 12, 2015). Docket 2014-0192.

17. Hawaii Public Utilities Commission. Decision and Order No. 34514 (April 27, 2017). Docket 2013-0141.

18. Arizona Corporation Commission. Commission approves energy efficiency programs that save APS customers money. June 15, 2016. https://azcc.gov/Divisions/Administration/news/ 2016Releases/7-13-2016\%20Commission\%20Approves\% 20Energy\%20Efficiency\%20Programs.pdf.

19. Bender D, Byrne R, Borneo D. ARRA energy storage demonstration projects: lessons learned and recommendations (June 2015). Sandia National Laboratory.

20. Balducci PJ, Hardy TD, Wu D, Viswanthan VV, Hutton III JJ, Craig PA. Washington Clean Energy Fund: Use case analysis project task 2.1 preliminary report outlining data needs for financial evaluation. Pacific northwest National Laboratory, 2015.

21. Hardy TD, Balducci PJ, Joshi K. Washington Clean Energy Fund: controller development project, task 1.1 preliminary report outlining data needs for controller development. Pacific Northwest National Laboratory, 2015.

22. Massachusetts Clean Energy Center, Advancing Commonwealth Energy Storage (ACES). Available at https://www.masscec.com/ advancing-commonwealth-energy-storage-aces.

23. Massachusetts Clean Energy Center and Massachusetts Department of Energy Resources Advancing Commonwealth Energy Storage (ACES) RFP Webinar presentation (April 2017). Available at http://
files.masscec.com/MassCEC\%20ACES\%20Informational\% 20Webinar\%20-\%20April\%202017_1.pdf.

24. SB 115 (2016), Utah State Legislature.

25. Rocky Mountain Power. Exhibit D: Solar and Energy Storage Program (September 2016). Filed in docket 16-035-36 of the Utah Public Service Commission.

26. New York REV Connect, About Rev Connect. Available at https:// nyrevconnect.com/about-rev-connect/\#\#.

27. New York State, REV Demo Projects. Available at https://rev.ny. gov/rev-demo-projects-1.

28. GTM Research, Energy Storage Association. U.S. In: Energy storage monitor: Q3 2018 executive summary; September 2018.

29. Hledik R, Zahniser-Word J, Cohen J. Storage-oriented rate design: stacked benefits or the next death spiral? Electr J. 2018: In press. https://doi.org/10.1016/j.tej.2018.09.012. This article presents the considerations and impacts involved in designing utility rates to incent behind-the-meter energy storage adoption.

30. Bayram IS, Ustun TS. A survey on behind the meter energy management systems in smart grid. Renew Sust Energ Rev. 2017;72: 1208-32. https://doi.org/10.1016/j.rser.2016.10.034.

31. California Public Utilities Commission. Self-Generation Incentive Program. Available at http://www.cpuc.ca.gov/sgip/.

32. Itron. 2017 SGIP advanced energy storage impact evaluation. September 7, 2008.

33. Arizona Corporation Commission. Opinion and order, dockets E-01345A-16-0036 and E-01345A-16-0123 (July 26, 2017).

34. Maryland Energy Administration. Energy Storage Tax Credit Program - Tax Year 2018. Available at https://energy.maryland. gov/business/Pages/EnergyStorage.aspx.

35. Maryland Energy Administration. Maryland Energy Administration Offers Pilot Program: "First in the Nation Energy Storage Tax Credit Program." Available at https:// news.maryland.gov/mea/2018/02/13/maryland-energyadministration-offers-pilot-program-first-in-the-nation-energystorage-tax-credit-program/.

36. AB 405 (2017), Nevada State Legislature.

37. SB 18-000 (2018), Colorado State Legislature.

38. Puget Sound Energy. 2017 Integrated Resource Plan.

39. Avista Corporation. 2017 Integrated Resource Plan.

40. Energy Information Administration. 2017 Form EIA-860 Data Schedule 3, 'Energy Storage Data' (Operable Units Only). Available at https://www.eia.gov/electricity/data/eia860/.

41. Bloomberg New Energy Finance New Energy Outlook 2018. Available at https://bnef.turtl.co/story/neo2018?teaser=true.

Publisher's Note Springer Nature remains neutral with regard to jurisdictional claims in published maps and institutional affiliations. 